\title{
E-Learning Moodle, Media Pembelajaran Fisika Abad 21
}

\author{
${ }^{1}$ Desak Made Anggraeni dan ${ }^{2}$ Ferdinandus Bele Sole \\ ${ }_{1}^{1}$ rogram Studi Pendidikan Fisika, STKIP Weetebula Jl. Mananga Aba, Sumba Barat \\ Daya-NTT, Indonesia \\ 2Program Studi PGSD, STKIP Weetebula Jl. Mananga Aba, Sumba Barat Daya-NTT, \\ Indonesia \\ Email: desak.madeanggraeni@gmail.com
}

\begin{tabular}{|c|c|}
\hline ARTICLE INFO & ABSTRACT \\
\hline $\begin{array}{l}\text { Article history } \\
\text { Received: March } 2018 \\
\text { Revised: April } 2018 \\
\text { Accepted: May } 2018 \\
\text { Published: June } 2018 \\
\\
\text { Keywords } \\
\text { moodle; } \\
\text { learning media }\end{array}$ & $\begin{array}{l}\text { [Title: Moodle E-Learning, the 21st Century Physics Learning Media] A } \\
\text { distinctive characteristic of 21st century learning is digital communication, meaning } \\
\text { that the learning process is no longer face to face course between teachers and students } \\
\text { but is more of an internet-based (e-learning) modern learning. The process of } \\
\text { implementing e-learning requires a Learning Management System (LMS) which } \\
\text { functions to regulate the management of learning. One of the LMS that can be used in } \\
\text { organizing e-learning learning is moodle. Moodle e-learning can be used as a medium } \\
\text { to improve the quality of interactive learning and support for the implementation of } \\
\text { blended learning. Through e-learning moodle learning material can be accessed anytime } \\
\text { and anywhere, besides that the material can be enriched with various learning resources } \\
\text { including multimedia, which can be quickly updated by the instructor. In addition, the } \\
\text { facilities offered in moodle e-learning learning are able to display learning materials that } \\
\text { are abstract in nature into material that can be witnessed in person. Material samples } \\
\text { that are mostly abstract are material on physics subjects. Therefore, moodle electronic } \\
\text { learning is expected to be able to help students master the concepts in physics learning. }\end{array}$ \\
\hline
\end{tabular}

$\begin{array}{ll}\text { INFO ARTIKEL } & \text { ABSTRAK } \\ \text { Sejarah Artikel } & \text { Karakteristik khas pembelajaran abad ke-21 adalah komunikasi digital, artinya } \\ \text { Dikirim: Maret 2018 } & \text { proses pembelajaran tidak lagi bersifat tatap muka (face to face course) secara } \\ \text { Direvisi: April 2018 } & \text { langsung antara guru dan siswa tetapi lebih bersifat pembelajaran modern } \\ \text { Diterima: Mei } 2018 & \text { berbasis internet (e-learning). Proses penyelenggaraan e-learning membutuhkan } \\ \text { Dipublikasi: Juni 2018 } & \text { sebuah Learning Management System (LMS) yang berfungsi untuk mengatur tata } \\ & \text { laksana penyelenggaraan pembelajaran. Salah satu LMS yang dapat digunakan } \\ \text { Kata kunci } & \text { dalam penyelenggaraan pembelajaran e-learning adalah moodle. E-learning } \\ \text { moodle; } & \text { moodle dapat digunakan sebagai media untuk meningkatkan kualitas } \\ \text { media pembelajaran } & \text { pembelajaran interaktif dan dukungan pada pelaksanaan pertemuan tatap } \\ & \text { muka di kelas (blended learning). Melalui e-learning moodle materi pembelajaran } \\ & \text { dapat diakses kapan saja dan dimana saja, disamping itu materi dapat } \\ & \text { diperkaya dengan berbagai sumber belajar termasuk multimedia dengan cepat } \\ \text { dapat diperbaharui oleh pengajar. Selain itu, fasilitas yang ditawarkan dalam } & \text { pembelajaran e-learning moodle adalah dapat menampilan materi-materi } \\ \text { pembelajaran yang bersifat abstrak menjadi materi yang dapat disaksikan } \\ \text { secara langsung. Contoh materi yang banyak bersifat abstrak adalah materi } \\ \text { pada mata pelajaran fisika. Oleh karena itu, pembelajaran elektronik moodle ini } \\ \text { diharapkan mampu membantu siswa menguasai konsep-konsep dalam } \\ \text { pembelajaran fisika. }\end{array}$

How to Cite this Article? Anggraeni, D., M \& Sole, F., B. (2018). E-Learning Moodle, Media Pembelajaran Fisika Abad 21. Jurnal Penelitian dan Pengkajian Ilmu Pendidikan: e-Saintika, 1(2), 57-65. 


\section{PENDAHULUAN}

Abad 21 yang dikenal semua orang sebagai abad pengetahuan yang merupakan landasan utama untuk berbagai aspek kehidupan. Paradigma pembelajaran abad 21 menekankan pada kemampuan siswa untuk berpikir kritis, mampu menghubungkan ilmu dengan dunia nyata, menguasai teknologi informasi, berkomunikasi dan berkolaborasi.

Pembelajaran Abad 21 merupakan pembelajaran yang mengintegrasikan kemampuan literasi, kecakapan pengetahuan, keterampilan dan sikap, serta penguasaan terhadap teknologi. Literasi menjadi bagian terpenting dalam sebuah proses pendidikan, peserta didik yang dapat melaksanakan kegiatan literasi dengan maksimal tentunya akan mendapatkan pengalaman belajar lebih dibanding dengan peserta didik lainnya. Literasi dalam pendidikan mencakup literasi informasi, literasi media dan literasi Information, Communicationa and Technology (ICT) atau TIK. Literasi media dan literasi TIK mengandung makna bahwa dalam pembelajaran guru harus melek dengan teknologi dalam mengembangkan media pembelajaran berbasis TIK.

Perkembangan berbagai media pembelajaran semakin pesat seiring dengan adanya kemajuan teknologi yang juga semakin pesat. Dinamika teknologi saat ini mencapai akselerasi yang luar biasa. Teknologi yang dipelajari beberapa tahun sebelumnya mulai tergantikan dengan teknologi yang baru termasuk berbagai cara pembelajaran secara konvensional.

Bentuk perkembangan teknologi informasi yang dapat dimanfaatkan sebagai media pembelajaran adalah menggunakan e-learning. E-learning merupakan inovasi yang dapat dimanfaatkan dalam proses pembelajaran, tidak hanya dalam penyampaian materi pembelajaran tetapi juga perubahan dalam kemampuan berbagai kompetensi peserta didik. Melalui e-learning, peserta didik tidak hanya mendengarkan uraian materi dari pendidik saja tetapi juga aktif mengamati, melakukan, mendemonstrasikan, dan sebagainya. Materi bahan ajar dapat divirtualisasikan dalam berbagai format sehingga lebih menarik dan lebih dinamis sehingga mampu memotivasi peserta didik untuk lebih jauh dalam proses pembelajaran.

Proses penyelenggaraan E-learning membutuhkan sebuah LMS yang berfungsi untuk mengatur tata laksana penyelenggaraan pembelajaran, didalam model E-learning (Priowijanto, 2010). LMS merupakan software pendukung dalam pembelajaran E-learning yang memiliki kemampuan untuk memanajemen kelas secara online, seperti pengelolaan dalam memberi tugas, materi pelajaran, evaluasi/ulangan dan lain sebagainya.

Salah satu LMS yang biasa digunakan untuk mengembangkan e-learning adalah Moodle. Pemanfaatan e-learning moodle sebagai media dalam pembelajaran fisika ini dimaksudkan untuk memenuhi tuntutan kecakapan literasi media dan TIK dalam pembelajaran abad 21. Artikel ini bertujuan untuk mendeskripsikan moodle sebagai media pembelajaran sesuai tuntutan pembelajaran abad 21.

\section{PEMBAHASAN}

\section{Pembelajaran abad 21}

Pembelajaran yang dikembangterapkan pada abad 21 adalah pembelajaran yang mampu mengembangkan kompetensi secara utuh, tidak saja membekali 
peserta didik dengan sejumlah core subject sesuai peminatan, tetapi juga perlu membekali dengan kompetensi non akademik yang lebih bersifat interpersonal dan intrapersonal. Pendidikan pada abad ini memiliki peran yang sangat penting karena dunia pendidikan dituntut untuk mampu menjamin peserta didik memiliki keterampilan belajar dan berinovasi, keterampilan menggunakan teknologi dan media informasi, serta dapat bekerja, dan bertahan dengan menggunakan kecakapan hidup (life skills).

Kasali (2013) dalam sosialisasi kurikulum 2013 menyampaikan tentang "tantangan Indonesia dalam abad ke 21". Kasali (2013) menyatakan ada 5 Tantangan Pendidikan Tinggi, yaitu (1) model-model pendidikan baru yang membawa kompetisi yang belum pernah terjadi sebelumnya dari model-model yang tradisional, (2) bentuk baru dalam penerbitan dan penelitian yang belum dipahami dengan baik oleh pengambil keputusan, (3) kita jauh dari melihat literasi media digital sebagai norma yang diharapkan untuk profesional akademik, (4) eksperimen dengan aplikasi teknologi yang inovatif sering dianggap sebagai peran luar dari seorang peneliti, dan (5) di dalam dunia Open Source, perpustakaan berada di bawah tekanan untuk mengembangi cara-cara baru untuk mendukung beasiswa.

Lima tantangan pendidikan tinggi yang dikemukakan Kasali di atas berkaitan dengan 3 literasi, yaitu literasi informasi, literasi media dan literasi TIK. Ketiga literasi ini merupakan bagian dari keterampilan abad 21. Sejalan dengan hal tersebut, Nuh (2013) menyatakan bahwa lingkungan belajar untuk tercapainya kompetensi abad 21 haruslah (1) menciptakan latihan pembelajaran, dengan dukungan SDM dan infrastruktur, (2) memungkinkan pendidik untuk berkolaborasi, berbagi pengalaman dan integrasinya di kelas, (3) memungkinkan peserta didik untuk belajar yang relevan dengan konteks dunia, dan (4) mendukung perluasan keterlibatan komunitas dalam pembelajaran, baik langsung maupun online.

Kecakapan dan ketrampilan serta melek literasi dibutuhkan dalam menghadapi tantangan abad 21. Rangkuman kerangka internasional kompetensi abad 21 yang dirumuskan oleh The Assesment and Teaching of 21st Century Skills (ATC21S) Project, meliputi (1) cara berpikir, terdiri atas kreativitas dan inovasi, berpikir kritis, problem solving, dan membuat keputusan; (2) cara bekerja, terdiri atas komunikasi dan kolaborasi; (3) perangkat bekerja, terdiri atas literasi informasi, dan literasi TIK; (4) hidup di dunia, terdiri atas kewarganegaraan lokal dan global, keterampilan hidup dan karir (mencakup adaptif terhadap perubahan, mengelola tujuan dan waktu, menjadi pembelajar mandiri, mengelola kegiatan/projek, bekerja efektif dalam tim, fleksibel, membimbing dan memimpin orang lain), tanggung jawab secara personal dan sosial (Ontario, 2016).

Fullan dan Scott (2014) mengidentifikasi kompetensi abad 21 ke dalam "The Six Cs", yaitu (1) Character education, mencakup karakter jujur, pengaturan diri dan tanggung jawab, tekun, empati untuk memberikan rasa aman dan kebermaknaan bagi orang lain, percaya diri, kepribadian yang sehat dan sejahtera, keterampilan hidup dan karir; (2) Citizenship, mencakup aspek pengetahuan global, sensitifitas dan respek terhadap budaya lain, aktif terlibat dalam kegiatan kemanusiaan dan lingkungan; (3) Communication, mencakup kemampuan berkomunikasi secara efektif baik dalam bentuk oral, tulis, dan pemanfaatan perangkat digital, serta 
keterampilan dalam mendengar; (4) Critical thinking and problem solving, berpikir secara kritis dalam merancang dan mengelola kegiatan (project), memecahkan masalah, dan membuat keputusan dengan memanfaatkan perangkat digital dan sumber yang bervariasi; (5) Collaboration, mencakup kemampuan bekerja dalam tim, belajar dari yang lain dan berkontrinbusi tehadap yang lain, keterampilan social networking, dan empati terhadap perbedaan dalam bekerja; (6) Creativity and imagination, mencakup kompetensi entrepeunership secara ekonomi dan sosial, memperhatikan dan mendorong lahirnya berbagai ide baru, dan kepemimpinan.

Herawati (2011) mengemukakan bahwa pengembangan kompetensi guru abad 21 terkait dengan teknologi, pedagogi, dan isi pembelajaran yang dibelajarkan atau Technological, Pedagogical, and Content Knowledge (TPACK). Guru/dosen perlu terus menerus meningkatkan pengetahuan dan keterampilannya membelajarkan siswa dan mahasiswanya dalam kerangka pikir TPCAK agar dapat membelajarkan siswa dan mahasiswanya secara efektif. Oleh karena itu guru/dosen perlu terus belajar sepanjang hayat agar dapat meningkatkan layanannya terhadap siswa dan mahasiswa yang dipercayakan kepadanya untuk dididik.

Beberapa langkah dan strategi diperlukan dalam upaya mewujudkan model pembelajaran yang relevan dan kondusif untuk menyiapkan peserta didik menjadi warganegara masyarakat gobal, masyarakat informasi, dan masyarakat pengetahuan abad 21 seperti.

1. Fokus pembelajaran pada praktik belajar lebih dalam (deeper learning) dan belajar kemitraan baru. Belajar lebih dalam adalah proses dimana individu menjadi mampu mengambil apa yang dipelajari dari satu situasi dan mengaplikasikannya pada situasi lain;

2. Strategi pembelajaran mengaplikasikan strategi pedagogi yang mendukung praktik deeper learning dan kemitraan baru. Untuk menyiapkan peserta didik mampu mencapai kesuksesan dalam masyarakat pengetahuan dan ekonomi yang dinamis yang dicirikan dengan kompleksitas, tidak terprediksi, keterhubungan global, perubahan yang sekaligus peluang, pembelajaran harus bergeser dari model pembelajaran langsung ke arah model pembelajaran penemuan (inquiry based model). Pembelajaran berbasis masalah merupakan salah satu strategi yang dapat dikembangkan, pembelajar tidak hanya mempresentasikan informasi tetapi dalam jangka panjang juga menjadikan peserta didik lebih terampil dalam pemecahan masalah (Ontario, 2016),

3. Pemanfaatan teknologi diarahkan pada upaya membantu peserta didik dalam mengembangkan keterampilan teknologis sebagai bagian dari kompetensi abad 21. Teknologi memungkinkan individu oleh memperoleh akses informasi (realtime data), memberikan simulasi tentang suatu objek sebagaimana adanya (real world), dan peluang untuk terkoneksi dengan berbagai objek belajar sesuai minat.

4. Pendidikan informal dan belajar pengalaman berperan penting dalam mengembangkan kompetensi peserta didik. Artinya pembelajaran yang dikembangterapkan bagi peserta didik harus mempertimbangkan pengalaman belajar yang diperoleh di luar kelas, dan perlu mengembangkan berbagai aktivitas untuk memperkaya pengalaman belajar peserta didik di luar kelas (Ontario, 2016). 
5. Assesmen dilakukan dengan pendekatan pedagogik transformatif. Assesmen yang dikembangkan untuk mendukung keberhasilan proses pembelajaran berorientasi pada pencapaian kompetensi abad 21, adalah yang mampu menjangkau seluruh aspek capain pembelajaran (Ontario, 2016). Assesmen autentik memungkinkan untuk mengkur capaian pembelajaran secara komprehensif, mulai dari dimensi kognisi, keterampilan, hingga sikap dan sistem nilai, tidak hanya beorientasi pada produk (capaian hasil) semata, tetapi juga dari dimensi proses pencapainya.

6. Dukungan infrastruktur pembelajaran berperan penting dalam pencapaian kompetensi abad 21. Ruang fisik di mana dan kapan peserta didik melakukan proses belajar menjadi faktor pendukung yang signifikan. Ruang fisik (physical space) mencakup aspek desain yang fleksibel, memfasilitasi keterhubungan yang konstruktif, konfigurasi perpustakaan yang menjadi pusat belajar, dan desain yang memudahkan berhunungan dengan dunia luar, dengan komunitas yang lebih luas (Ontario, 2016).

Berdasarkan langkah dan/atau strategi di atas, diharapkan dapat mewujudkan suatu model pembelajaran yang mampu menjadikan peserta didik aktif belajar untuk membangun pengetahuan, keterampilan, dan sikap sesuai tuntutan perubahan dan tantangan jaman. Salah satu kecakapan yang diharapkan dikuasai oleh guru dalam menghadapi pembelajaran abad 21 adalah literasi yakni literasi informasi, literasi media dan literasi TIK. Tiga bagian literasi ini menjadi hal penting yang harus dimiliki agar menjadi bekal bagi guru agar menjadi melek literasi. Guru diharapkan mampu memanfaatkan media dan TIK dalam pembelajaran misalnya dengan memanfaatkan e-learning moodle dalam kaitannya dengan literasi media dan literasi TIK.

\section{Hakikat e-learning moodle}

Secara etimologi, Kata e-learning terdiri dari dua bagian, yaitu $e$ yang merupakan singkatan dari electronic dan learning yang berarti pembelajaran. Jadi, $e-$ learning dapat diartikan sebagai pembelajaran dengan menggunakan jasa bantuan perangkat elektronika, khususnya perangkat komputer. E-learning sering disebut juga dengan online course. Online course secara sederhana dapat didefinisikan sebagai pembelajaran di kelas maya, namun pada penerapannya, pembelajaran tidak hanya mengandalkan online course tetapi juga pembelajaran di kelas melalui tatap muka.

E-learning merupakan bagian dari Integrated Learning Design Framework (ILDF). Model ILDF adalah model desain pembelajaran yang khusus dikembangkan untuk proses belajar masa depan, yaitu online e-learning atau web-based learning yang mengoptimalkan pemanfaatan teknologi telekomunikasi. Model e-learning dikatakan termasuk dalam model ILDF karena memiliki ciri khas yang sesuai dengan model ini. Ciri khas model ILDF adalah berorientasi pada proses belajar menggunakan virtual classroom, mengangkat masalah yang perlu dihilangkan batasan waktu dan geografisnya, dan jenis pembelajaran yang disusun berupa pembelajaran mandiri dengan konten yang biasa ada pada pembelajaran di kelas dengan sistem tatap muka (Prawiradilaga, 2008). 
E-learning merupakan salah satu bentuk model pembelajaran yang difasilitasi dan didukung pemanfaatan teknologi informasi dan komunikasi. Menurut Clark dan Mayer (2008) E-learning mempunyai ciri-ciri sebagai berikut.

1. Memiliki konten yang relevan dengan tujuan pembelajaran;

2. Menggunakan metode instruksional, misalnya penyajian contoh dan latihan untuk meningkatkan pembelajaran;

3. Menggunakan elemen-elemen media seperti kata-kata dan gambar-gambar untuk menyampaikan materi pembelajaran;

4. Memungkinkan pembelajaran langsung berpusat pada pengajar (synchronous elearning) atau di desain untuk pembelajaran mandiri (asynchronous e-learning);

5. Membangun pemahaman dan keterampilan yang terkait dengan tujuan pembelajaran baik secara perseorangan atau meningkatkan kinerja pembelajaran kelompok.

Pembangunan dan pengembangan e-learning saat ini begitu mudahnya dengan perangkat lunak learning management system (LMS) yang disebut moodle. Fitur-fitur penting penunjang pembelajaran tersebut misalnya tugas, quiz, komunikasi, kolaborasi, serta fitur utama yang dapat mengupload berbagai format materi pembelajaran (Surjono, 2011). Pendidik dituntut untuk menciptakan suasana belajar yang efektif, inovatif, dan menyenangkan. Pendidik berperan sebagai motivator dan fasilitator dalam proses pembelajaran. Perubahan paradigma instructional based learning menjadi constructional based learning membuat pendidik harus mendesain pembelajaran yang mengaktifkan peserta didik untuk lebih banyak mengasah skill dengan praktik mandiri.

Moodle merupakan perangkat lunak open source yang mendukung implementasi e-learning dengan paradigma terpadu dimana berbagai fitur penunjang pembelajaran dengan mudah dapat diakomodasi dalam suatu portal $e-$ learning (Surjono, 2011). Cole dan Foster (2008) mendefinisikan Moodle sebagai singkatan dari Modular Object-Oriented Dynamic Learning Environment yang berarti tempat belajar dinamis dengan menggunakan model berorientasi objek. Aplikasi Moodle pertama kali dikembangkan oleh Dougiamas (2002) dengan Moodle versi 1.0. Saat ini, Moodle bisa dipakai oleh siapa saja secara open source.

Menurut Amin (2012), Moodle merupakan salah satu paket software yang digunakan untuk mengembangkan system dan proses pembelajaran dengan menggunakan perangkat komputer (laptop) dan gadget lainnya. Hasil pengembangan moodle ini selanjutnya dapat diakses oleh pelajar dengan memanfaatkan jaringan internet. Sistem dan proses pembelajaran dengan memanfaatkan aplikasi ini disebut sebagai Learning Management System (LMS) atau Course Management System (CMS).

Priowirjanto (2010) menjelaskan bahwa ada beberapa alasan yang menjadikan moodle sebagai salah satu LMS yang digunakan oleh banyak institusi pendidikan, antara lain.

1. Free and open source. Moodle bernaung dibawah bendera open source, sehingga dengan demikian semua orang dapat memodifikasi sesuai dengan kebutuhan dari institusi yang menggunakan. Moodle didistribusikan secara gratis, sehingga tidak membutuhkan dana untuk membekali aplikasinya, kecuali dana yang 
dibutuhkan untuk membayar bandwith yang terpakai untuk mendownload $15 \mathrm{MB}$ master moodle.

2. Ukuran kecil, kemampuan maksimal. Ukuran kapasitas dalam moodle kecil (sekitar $15 \mathrm{MB}$ ) namun mampu mengadakan aktifitas kegiatan akademik dan pembelajaran hingga seukuran 50.000 orang.

3. Dilandasi oleh Educational Philosophy. Moodle tidak dibangun oleh seorang ahli komputer murni, tetapi berdasarkan pengalaman dan latar belakang tenaga pendidik. Moodle mampu mengakomodir hampir semua kebutuhan pendidikan konvensional yang ditransfer dalam wujud online learning.

4. Mempunyai komunitas yang besar dan saling berbagi.

Adapun komponen pembelajaran yang diaplikasikan kedalam program pembelajaran berbasis moodle, diantaranya.

1. Materi pembelajaran dalam moodle. Pembelajaran yang bersifat online menuntut adanya bahan ajar berbasis web yang mempunyai karakteristik khusus sesuai dengan karakteristik web itu sendiri. Salah satu karakteristik yang paling menonjol adalah adanya fasilitas hyperlink. Hyperlink memungkinkan sesuatu subyek merujuk ke subyek lain tanpa ada batasan fisik dan geografis, selama subyek yang bersangkutan tersedia pada web. Dengan adanya fasilitas hyperlink maka sumber belajar menjadi sangat kaya. Search engine sangat membantu untuk mencari subyek yang dapat dijadikan link.

2. Media Pembelajaran Berbasis Moodle. Media pembelajaran merupakan alat bantu dalam pembelajaran. Keberadaan media, baik yang berupa audio maupun visual dapat membentuk pemahaman yang konkrit dari sebuah penjelasan yang abstrak.

3. Evaluasi dan Penugasan dalam Moodle. Penggunaan program komputer sebagai alat bantu evaluasi, mencakup kemampuan (1) latihan soal, mencakup soal-soal yang dapat berkembang setiap saat sesuai dengan persiapan dari guru; (2) kuis dan evaluasi, mencakup komponen yang berisi soal-soal seperti dalam proses pembelajaran pada umumnya; (3) tanya jawab interaktif dan diskusi, proses pembelajaran tidak hanya dilakukan untuk adanya diskusi dan interaksi secara langsung ataupun tidak langsung antara guru dan siswa. Untuk itu, satu forum diskusi yang terbuka untuk keseluruhan peserta akan dapat membuat dan mengembangkan wawasan dari siswa secara umum.

\section{Contoh media moodle dalam pembelajaran fisika}
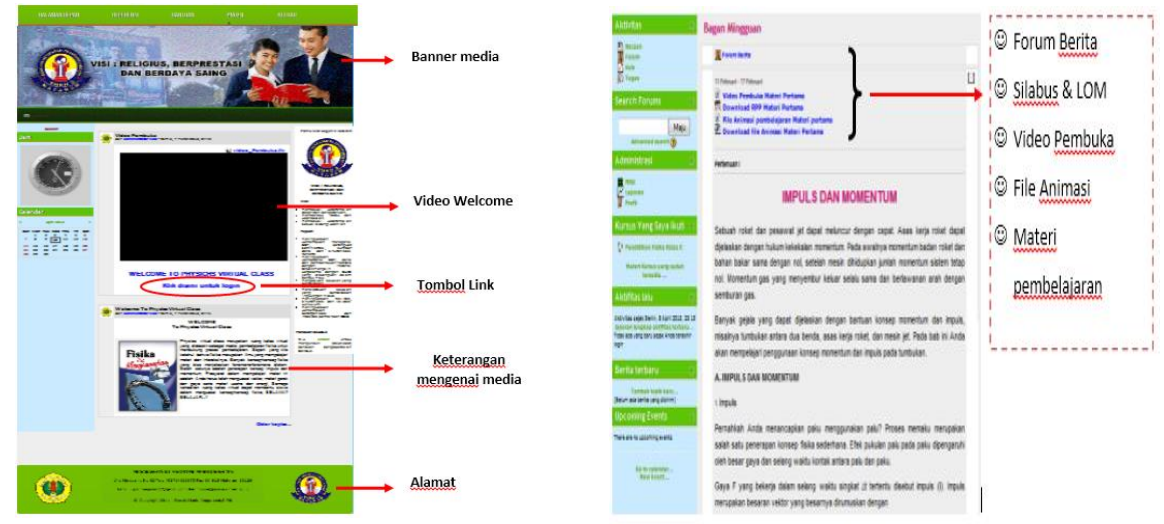

Gambar 1. Halaman kursus 


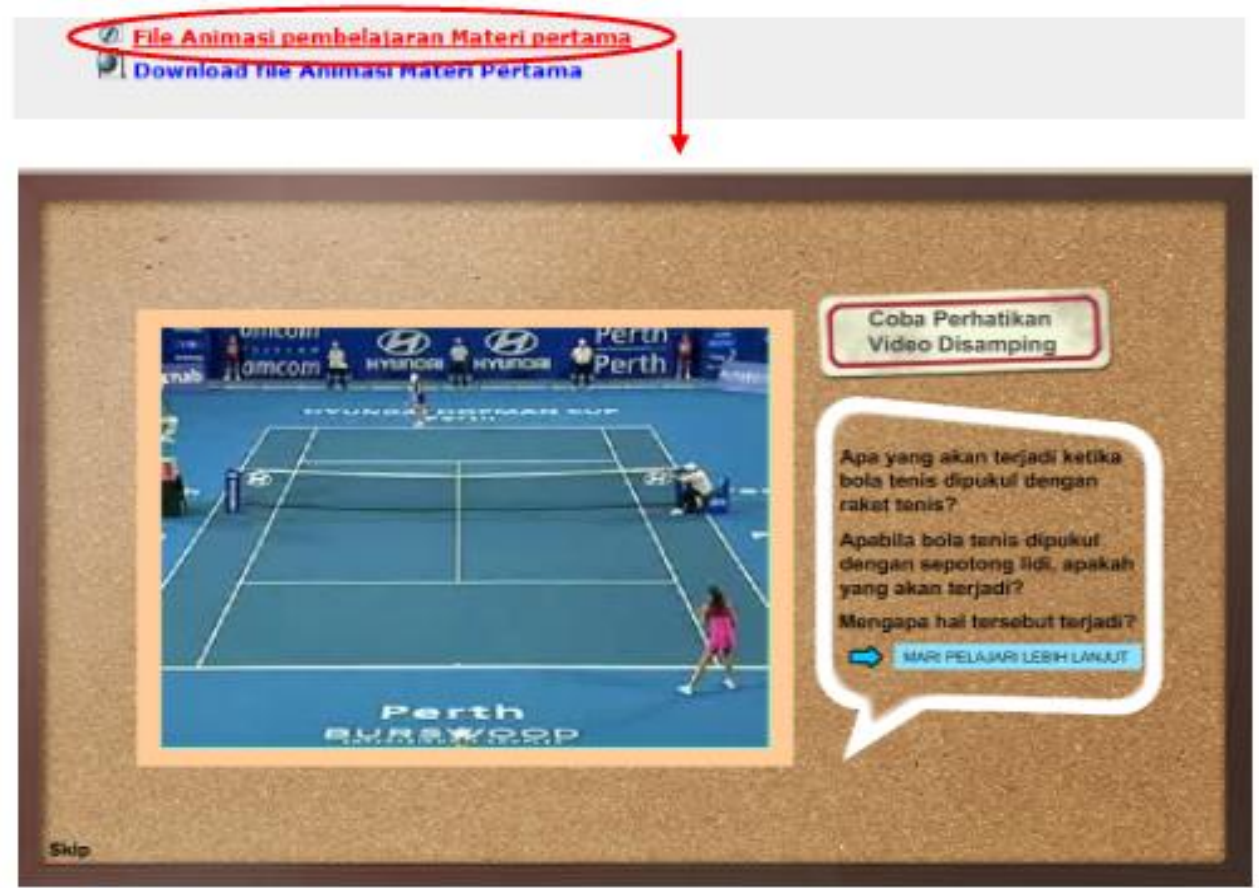

Gambar 2. Animasi pembelajaran

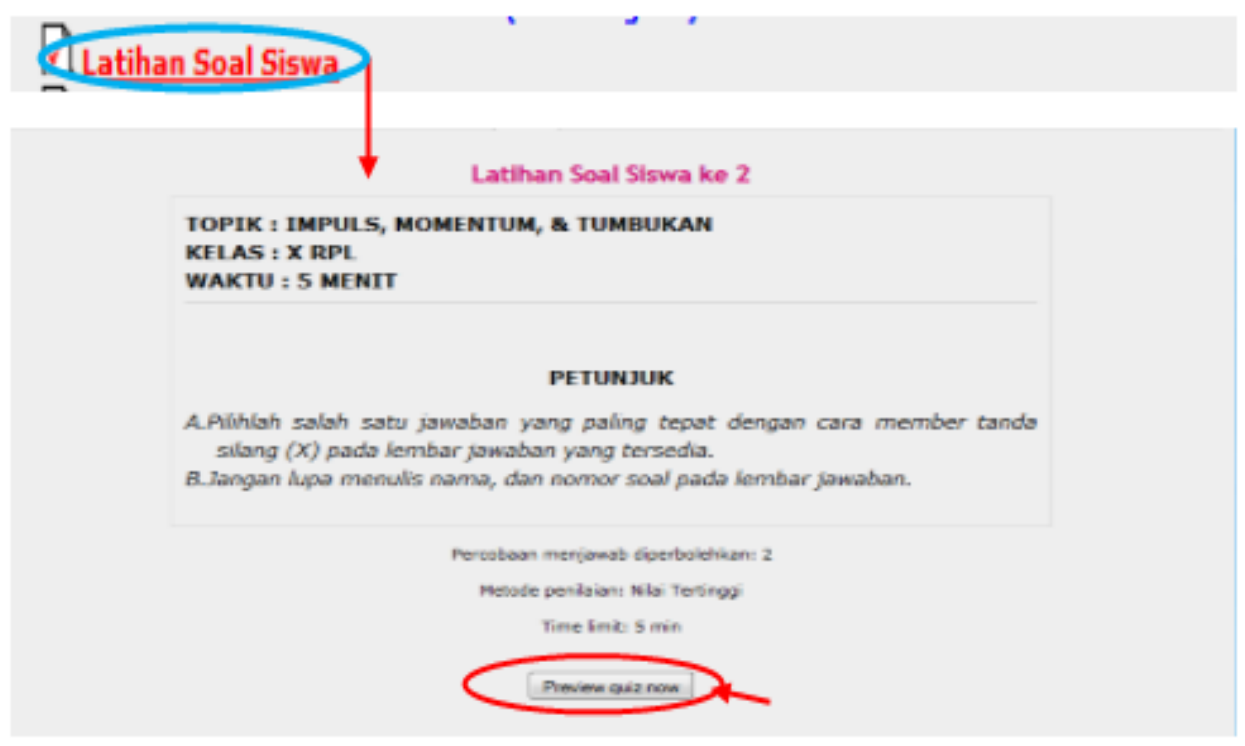

Gambar 3. Latihan soal

\section{PENUTUP}

E-learning moodle sebagai media pembelajaran dapat difungsikan sebagai pelengkap (komplemen) maupun suplemen untuk meningkatkan pembelajaran di dalam kelas sehingga dapat membantu meningkatkan pemahaman siswa terhadap materi dan meningkatkan kegiatan pembelajaran di sekolah. Pemanfaatan Teknologi sebagai media dalam pembelajaran merupakan implementasi pembelajaran pada abad 21 dimana siswa dilatih menguasai literasi media dan juga literasi ICT. 


\section{DAFTAR PUSTAKA}

Clark, R., C \& Mayer, R., E. (2008). E-learning and the science of instruction: proven guidelines for consumers and designers of multimedia learning, second edition. San Francisco: John Wiley \& Sons, Inc.

Fullan, M. (2014). Great to Excellent: Launching the next stage of Ontario,s education agenda. Diunduh Mei 2018 dari http://michaelfullan.ca/great-to-excellentlaunching-the-next-stage-of-ontarios-education-agenda/.

Herawati. (2011). Blended Learning untuk Menyiapkan Siswa Hidup di Abad 21. Makalah Seminar Nasional 2011, Pengembangan Pembelajar-an berbasis Blended Learning. Universitas Negeri Malang.

Kasali, R. (2013). Tantangan Indonesia Dalam Abad ke21 (Mengapa Kita Harus Siap Berubah?). Disampaikan dalam sosialisasi kurikulum 2013. Pe-nyegaran Nara Sumber Pelatihan Guru untuk Implementasi Kuri-kulum 2013. Jakarta, 26-28 Juni 2013.

Nuh, M. (2013). Pengembangan Kurikulum 2013. Disampaikan dalam sosialisasi kurikulum 2013. Penyegaran Nara Sumber Pelatih-an Guru untuk Implementasi Kurikulum 2013. Jakarta, 26-28 Juni 2013.

Ontario Ministry of Education. (2016). 21st Century Competencies: Towards defining 21st Century Competencies for Ontario. Toronto: Author. Diunduh April 2018 dari www.ksbe.edu/_assets/spi/pdfs/21_century_skills_full.pdf.

Priowirjanto, dkk. (2010). Panduan Learning Management System: Mengembangkan Bahan Ajar Berbasis Web dengan Software Moodle. Jakarta : Seamolec.

Rusman, dkk. (2011). Pembelajaran berbasis teknologi informasi dan komunikasi, mengembangkan profesionalitas guru. Jakarta: PT. Raja Grafindo.

Seok, S. (2008). The aspect of e-learning. International Journal on ELearning, Proquest, $7(4), 725-741$. 